Please cite this article as:

von Briel, D. \& Dolnicar, S. (2020). The evolution of Airbnb regulation - An international longitudinal investigation 2008-2020. Annals of Tourism Research, https://doi.org/10.1016/j.annals.2020.102983

\title{
THE EVOLUTION OF AIRBNB REGULATION An International Longitudinal Investigation 2008-2020
}

Dorine von Briel \& Sara Dolnicar

Tourism | UQ Business School | The University of Queensland | Australia

\section{Introduction}

Peer-to-peer accommodation has been extensively studied over the past decade. The area that has most fascinated researchers - and most challenged policy-makers - is how to regulate peer-to-peer accommodation to avoid negative side effects, without restricting economic benefits (Dolnicar, 2019). Regulations are typically reported as individual case studies at one point in time (Hajibaba \& Dolnicar, 2017), yet they continuously evolve, sometimes radically, as in the case of Tasmania (Grimmer, Vorobjovas-Pinta \& Massey, 2019).

This is the first longitudinal investigation of Airbnb regulations. It develops a typology of destinations based on their regulatory reaction to Airbnb, and identifies key regulatory aims, and specific measures for policy makers to achieve those aims.

Our study focuses on popular tourist destinations affected by the normalisation of peer-topeer accommodation: San Francisco, New York, Amsterdam, London, Berlin, Paris, Barcelona, Reykjavik, Vienna, Tokyo and Hobart. These destinations experienced reduced quality of life for residents (Sheppard \& Udell, 2016), reduced housing availability (Ferreri \& Sanyal, 2018) and affordability (Zale, 2018), a change in the character of neighbourhoods (Zale, 2018), additional competition for hospitality businesses (Davidson \& Infranca, 2018), and potential safety risks for guests (Guttentag, 2015). Residents, commercial accommodation providers and local governments reacted by lobbying against Airbnb. Anyone benefitting from Airbnb (hosts, entrepreneurs and councils earning revenue) supported Airbnb's global lobbying campaign. This tension led destinations to introduce formal regulations.

Based on academic publications, media reports and policy documents, we create a chronological summary of regulatory responses and identify generalisable patterns. Four types of responses emerge: regulation and taxation, introduction of a registration system, refinement and modification of regulations, and collaborative initiatives of governments and platform facilitators. We use these responses to track the evolution of Airbnb regulation.

\section{Regulatory reactions}

Half of the cities under investigation (San Francisco, Hobart, Vienna, London, Tokyo, Reykjavik) had strict short-term accommodation regulations in place before peer-to-peer 
accommodation became a mass phenomenon (Figure 1). Law scholars refer to this situation as end-run: an existing law ambiguously covers an innovation (Biber et al., 2017). In end-run situations, a business innovation flourishes despite being illegal under a pre-existing law: peerto-peer accommodation providers argue that their business is not illegal because it is new, and therefore not covered by existing laws. Many hosts ask for forgiveness, not for permission (Irwin, 2014). End-run cities typically introduce regulations with a delay. As pressure from hosts, tourists and peer-to-peer accommodation providers increases, end-run cities replace strict regulations with more flexible alternatives (Cutler, 2014; Deregulation Act 2015).

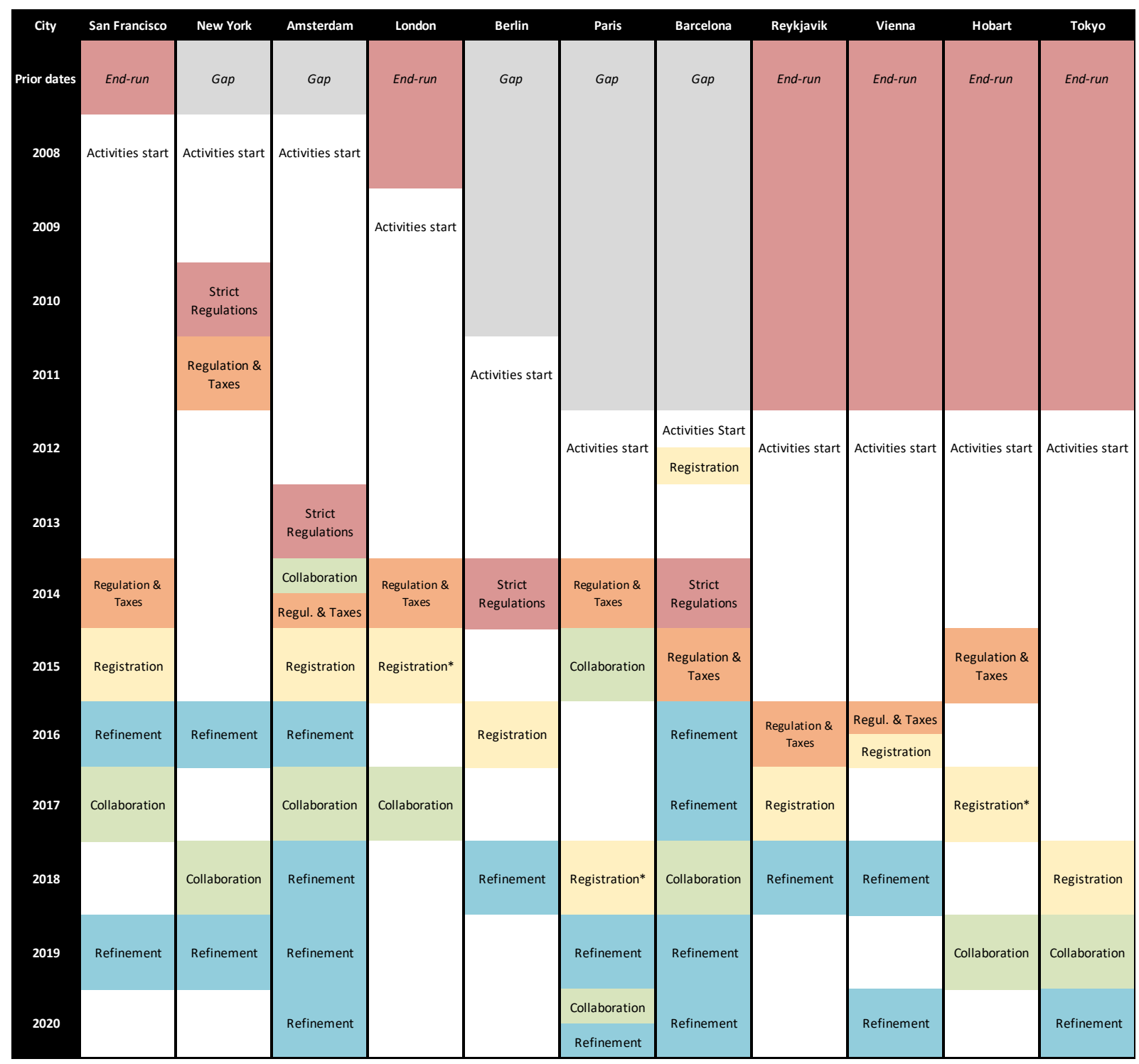

Figure 1. Comparative evolution of Airbnb regulation

A second group of cities (Paris, Amsterdam, Barcelona, New York, Berlin) faced a gap situation: existing legislation did not cover peer-to-peer accommodation (Biber et al., 2017). Gap 
cities create new policies. New York and Barcelona took regulatory action swiftly to protect the residential market. Barcelona introduced a registration system, followed by strict regulation two years later (Espiga, 2015). In Amsterdam a judge ruled an Airbnb host as illegal, setting a legal precedent that forced regulators to take action. Berlin and Paris reacted to negative externalities for residents; Paris with moderate, Berlin with strict measures.

Using the theoretical framework from law theory about policy disruptions initiated by business innovation (Biber et al., 2017), we rated regulatory strictness for all cities and all years ( 1 =unregulated, $10=$ extremely restrictive regulations, Figure 2$)$.
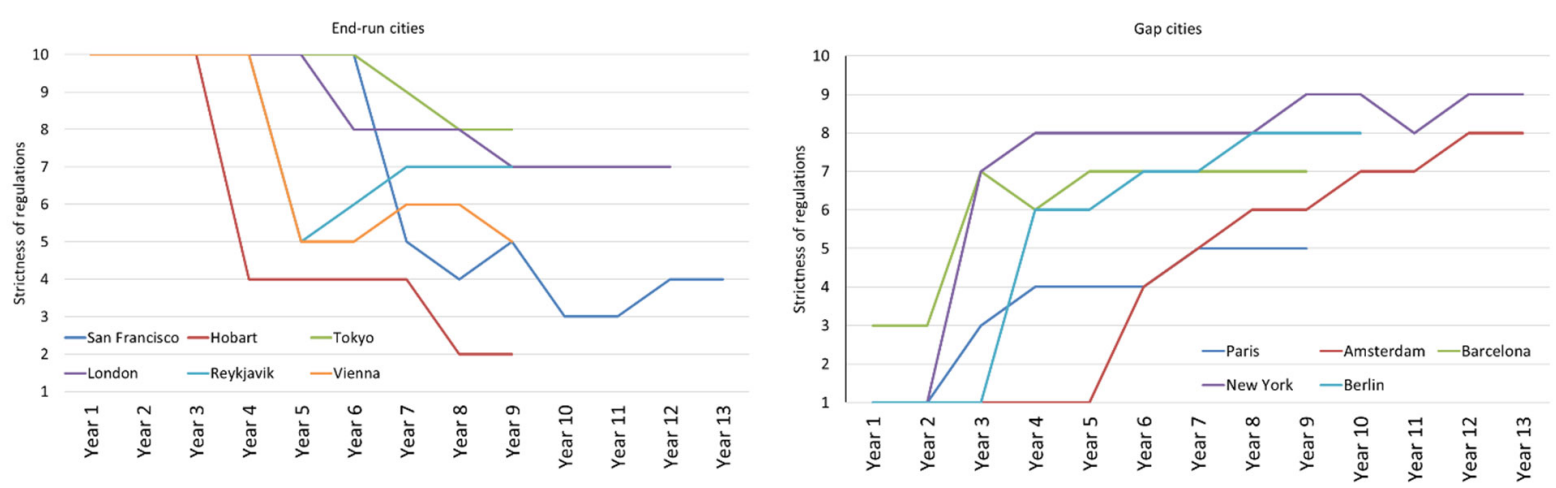

Figure 2. Regulatory evolution patterns

All end-run cities are strict initially, and loosen restrictions over time, typically in multiple stages. All gap cities tighten regulations over time, incrementally. There is substantial heterogeneity among end-run and gap cities, warranting the development of a finer typology.

\section{A typology of regulatory reactions to Airbnb}

We propose four types of cities: liberal, moderate, moderate-collaborative and protective. San Francisco and Hobart represent liberal cities where judges (Dwoskin, 2017), legislators, users and residents initially argue whether regulation should be strict or not, ultimately implementing generous regulatory frameworks. In San Francisco, for example, Mayor Ed Lee, advocated for Airbnb (Hamilton, 2015), leading to Airbnb being certified to register hosts with the Office of Short-Term Rentals and remit occupancy tax on their behalf. Hobart developed strict regulations, but ultimately - after extensive lobbying by Airbnb and hosts - opted for a lenient framework (Grimmer, Vorobjovas-Pinta \& Massey, 2019) relying on Airbnb to supply host data. Most other cities control data by using their own registration system, possibly a consequence of Airbnb having been accused of providing incomplete or wrong data to the city of New York (Fermino, 2015).

Moderate cities (Paris, Vienna) observe the impacts of peer-to-peer accommodation before introducing restrictions, and systems for tax and data collection. Moderate collaborative cities (Amsterdam, Barcelona) are willing to work with platform facilitators and communities as soon as peer-to-peer accommodation becomes available. Amsterdam was the first city to sign a memorandum of understanding (MoU, 2014). Barcelona - despite its reputation of being 
overwhelmed by Airbnb - has also taken a collaborative approach. Barcelona creates tourism plans in collaboration with tourism stakeholders, including platform facilitators (Castro Betancourt, 2018). Plans are reviewed and updated regularly, and caps set for the number of licences. Hotels, B\&Bs and Airbnb operate under the same licence. More licences have been awarded to peer-to-peer traded spaces in recent years (PEUAT, 2017). Because moderate collaborative cities modify regulations as part of their tourism planning process, they revise rules frequently.

Protective cities include Tokyo, London, Reykjavik, New York and Berlin. They regulate shortterm rentals heavily, placing restrictions on when, how and where they can operate. Regulations are rarely revised. Reykjavik is the least protective; its registration system automatically checks zoning compliance, and maximum earnings are set for hosts. Tokyo, London, and New York are the strictest cities, authorising only a limited number of councils (and buildings) to operate shortterm rentals. Unhosted rentals are forbidden in New York and Berlin. Yet, peer-to-peer accommodation trading is flourishing in these cities; the industry adapts to the strict regulations.

For all types of cities, Airbnb regulation does not affect listings in the long term. They drop only temporarily in response to fines imposed because of illegal listings. In 2014, 72\% of New York City listings were illegal (Streitfeld, 2014). Amsterdam had some 6,000 illegal Airbnb listings in 2016 (Van Heerde, 2017), Barcelona 6,275 (Lomas, 2016). In Berlin, 40\% of Airbnb listings disappeared overnight (O'Sullivan, 2016) when the maximum fine was raised to $€ 600,000$. In San Francisco, expensive registration and fines reduced listings from 10,000 to 5,500 (Said, 2018). In New York City, listings dropped from 20,000 to 300 in response to fines (Gebicki, 2017). Listings recovered quickly, in New York City to 36,888 within a month (Dobbins, 2017).

\section{Regulatory aims and measures designed to achieve them}

Policy makers around the world can learn from cities that have already formulated key regulatory aims and put in place measures to achieve them:

AIM \#1: ENSURE HOUSING FOR RESIDENTS. Sufficient and affordable housing for residents can be ensured by prohibiting unhosted rentals, prohibiting hosting in government subsidised housing, limiting the number of days for short-term rentals, and having a licencing system which involves a regular review and adjustment of available licences.

AIM \#2: ENSURE QUALITY OF LIFE FOR RESIDENTS. Most cities have a council-managed system for residents to report a disruption from short-term letting, or non-compliant activity. Only Tokyo, San Francisco and Barcelona have specific offices for this purpose.

AIM \#3: ENSURE GUEST SAFETY. Guest safety is typically managed by hosts self-declaring compliance with building regulations, and confirming safety devices - such as fire alarms, fire extinguishers, gas shutoff valves, and signage pointing to fire exits. Some cities require proof of public liability insurance. Tokyo checks premises for safely compliance; the fire department has to issue a certificate of compliance.

AIM \#4: INFORM CITY PLANNING. City planning relies on registration systems. Councils collect the following data: name of the host, address, telephone number, whether the listing is hosted or unhosted, whether the listing is the host's main place of residence. Some registrations require self-assessment of zoning compliance. When registrations are compulsory, hosts have to display registration numbers on their listings. 
AIM \#5: ENSURE APPROPRIATE TAXATION. About half of the cities with registration systems ask hosts to provide their tax file number. In some cities (e.g. Vienna) hosts have to declare bookings and pay the tourist tax directly to the city council. In other cities (e.g. San Francisco, Amsterdam, London) Airbnb remits the tourist tax on behalf of hosts.

AIM \#6: ENSURE THE INDEPENDENCE OF THE REGULATOR AND THE INDUSTRY. Most cities collect their own data. Very few - Hobart, for example - rely on data provided to them by Airbnb.

\section{Conclusion}

Short-term rental regulation is necessary when high tourism demand puts pressure on local residents. Cities experiencing such negative externalities have - over the years - all introduced regulations. Most use a simple registration system forcing hosts to declare their activities. Some hosts pay tourist taxes directly to the council, some pay via Airbnb. Many regulatory frameworks evolve over time, some are reviewed and modified regularly. Many cities collaborate with peerto-peer trading platform, even if tensions existed initially.

Lobbying emerges as the main driver of regulatory changes in end-run cities. In gap cities, regulations are typically motivated by legislators wanting to clarify the legal status of peer-topeer accommodation.

The impact of regulations on Airbnb listings is minimal. While listing numbers drop in response to major regulatory changes (especially fines), they recover quickly. As a consequence, Airbnb regulation does not affect key tourism industry KPIs. The destinations investigated in this study experienced a continuous increase in international visitors, irrespective of changes in Airbnb regulation. In London, the number of overnight visitors dropped from 2015 to 2016 - despite peer-to-peer accommodation being deregulated during this time. This has important practical implications: at destinations where tourism demand is high enough to cause negative externalities, the peer-to-peer accommodation sector is resilient enough to adjust to any regulations imposed by policy makers.

\section{References}

Biber, E., Light, S.E., Ruhl, J.B., \& Salzman, J. (2017) Regulating business innovation as policy disruption: From the model T to Airbnb. Vanderbilt Law Review, 70, 1561.

Castro Betancourt, S. (2018) Towards sustainable tourism in Barcelona. Retrieved 1.3.2020, https://www.onlinemarketplaces.com/articles/19034-towards-sustainable-tourism-inbarcelona-airbnb-eliminates-2-500-ads-during-2017.

Cutler, K.M. (2014) San Francisco legalizes. Retrieved 28.2.2020, https://techcrunch.com/2014/10/07/san-francisco-airbnb/.

Davidson, N., \& Infranca, J. (2018). The Place of the Sharing Economy. In N. Davidson, M. Finck, \& J. Infranca (Eds.). The Cambridge Handbook of the Law of the Sharing Economy. Cambridge: Cambridge University Press.

Deregulation Act (2015) Deregulation Act 2015. Retrieved 28.2.2020, http://www.legislation.gov.uk/ukpga/2015/20/pdfs/ukpga_20150020_en.pdf.

Dobbins, J. (2017). Making a living with airbnb. The New York Times. Retrieved 4.6.2020, https://www.nytimes.com/2017/04/07/realestate/making-a-living-with-airbnb.html. 
Dolnicar, S. (2019) A review of research into paid online peer-to-peer accommodation. Annals of Tourism Research, 75, 248 - 264.

Dwoskin, E. (2017) Airbnb's battle with San Francisco. Retrieved 28.2.2020, https://www.washingtonpost.com/news/the-switch/wp/2017/05/02/airbnbs-battle-with-sanfrancisco-shows-the-payoff-to-going-up-against-regulators/.

Espiga, F. (2015) Barcelona licence freeze. Retrieved 28.2.2020, https://www.cataloniatoday.cat/article/106-news-today/872978-barcelona-licencefreeze.html.

Fermino, J. (2015) Airbnb releases data on NYC apartments. Retrieved 28.2.2020, https://www.nydailynews.com/new-york/nyc-airbnb-users-breaking-law-report-article1.2451722 .

Ferreri, M., \& Sanyal, R. (2018) Platform economies and urban planning. Urban Studies, 55(15), 3353-3368.

Gebicki, M. (2017) Major blow for Airbnb users. Retrieved 4.3.2020 $\mathrm{http}$ ://www.theherald.com.au/story/4444330/major-blow-for-airbnb-users-new-law-torestrict-new-york-city-apartment-rentals.

Grimmer, L., Vorobjovas-Pinta, O., \& Massey, M. (2019) Regulating, and then deregulating Airbnb. Annals of Tourism Research, 75, 304-307.

Guttentag, D. (2015) Airbnb: Disruptive innovation and the rise of an informal tourism accommodation sector. Current Issues in Tourism, 18(12), 1192-1217.

Hajibaba, H. \& Dolnicar, S. (2017) Regulatory reactions around the world, in S. Dolnicar, Peerto-peer accommodation networks: Pushing the boundaries, Oxford: Goodfellow Publishers, pp. 120-136.

Hamilton, R. (2015) Airbnb wins in San Francisco. Retrieved 28.2.2020, https://www.latimes.com/local/lanow/la-me-ln-sf-results-airbnb-ballot-measure-20151103story.html.

Irwin, N. (2014) Ask forgiveness, not permission. Retrieved 1.3.2020, https://www.nytimes.com/2014/04/23/upshot/for-start-ups-looking-to-disrupt-regulatedindustries-the-new-strategy-is-ask-forgiveness-not-permission.html.

Lomas, N. (2016). Airbnb faces fresh crackdown in Barcelona. Retrieved on 15.02.2020https://techcrunch.com/2016/09/19/airbnb-faces-fresh-crackdown-inbarcelonaas-city-council-asks-residents-to-report-illegal-rentals/.

MoU (2014) Memorandum of understanding. Retrieved 28.2.2020, https://www.binnenlandsbestuur.nl/Uploads/2016/2/2014-12-airbnb-ireland-amsterdammou.pdf.

O'Sullivan, F. (2016) Europe's crackdown on Airbnb. Retrieved 11.6.2020, https://www.citylab.com/equity/2016/06/european-cities-crackdown-airbnb/487169/.

PEUAT (2017) About the special tourist accommodation plan. Retrieved 1.3.2020, https://ajuntament.barcelona.cat/pla-allotjaments-turistics/en/. 
Said, C. (2018) Airbnb listings in San Francisco plunge by half. Retrieved 4.6.2020, https://www.sfchronicle.com/business/article/Airbnb-listings-in-San-Francisco-plunge-byhalf-12502075.php.

Sheppard, S. \& Udell, A. (2016) Does Airbnb properties affect house prices? Retrieved 24.05.2020 web.williams.edu/Economics/wp/SheppardUdellAirbnbAffectHousePrices.pdf.

Streitfeld, D. (2014). Airbnb listings mostly illegal. New York State contends. Retrieved 28.02.2020 https://www.nytimes.com/2014/10/16/business/airbnb-listingsmostly-illegalstate-contends.html.

Van Heerde, J. (2017). Thousands of houses in Amsterdam are permanently occupied by tourists. Retrieved 28.02.2020 . Last accessed https://www.trouw.nl/nieuws/duizenden-huizen-inamsterdam-zijn-blijvend-bezet-door-toeristen $\sim$ baadec $19 /$.

Zale, K. (2018) Scale and the sharing economy. In N. Davidson, M. Finck, \& J. Infranca, The Cambridge Handbook of the Law of the Sharing Economy. Cambridge: Cambridge University Press, pp. 38-50. 